\title{
ReLAInEP
}

\section{A PERCEPÇÃO DO ALUNO DO CURSO DE ADMINISTRAÇÃO DA FACULDADE VALE DO IPOJUCA (FAVIP/DEVRY) SOBRE A FORMA ADEQUADA DE DESCARTE E REUSO DO LIXO ELETRÔNICO}

\author{
Lucyanno Moreira Cardoso de Holanda ${ }^{1}$ \\ Henrique de Queiroz Chaves ${ }^{2}$ \\ Renato Henrique Loreto da Mota ${ }^{3}$ \\ Antonio Carlos de Francisco ${ }^{4}$
}

\begin{abstract}
RESUMO: O presente trabalho tem por objetivo tratar do problema do lixo eletrônico e da importância de seu correto descarte e reuso isso através de um estudo de caso realizado com os alunos do curso de Administração da Faculdade do Vale do Ipojuca (FAVIP/DEVRY). Os procedimentos metodológicos utilizados no estudo foram à pesquisa aplicada, qualitativa, descritiva e estudo de caso. A população trata dos estudantes do Curso de Administração, matriculados no semestre de 2012.2, representando (530) quinhentos e trinta alunos. Já a amostra é caracterizada como casual simples, na medida em que cada elemento da população teve igual oportunidade de ser incluída, essa é composta de 110 alunos. O instrumento utilizado para coleta de dados constituiu de um questionário composto de seis perguntas com o objetivo primordial de verificar a percepção dos alunos sobre a forma de descarte e reuso do lixo eletrônico. Através das informações obtidas é possível inferir que a percepção dos alunos acerca da forma correta do descarte e reuso do lixo eletrônico ainda é confusa, tendo em vista que se pôde comprovar que a grande maioria dos entrevistados não possui conhecimento aprofundado do que é lixo eletrônico, das suas consequências negativas para o meio ambiente e para a saúde dos seres vivos, bem como podem realizar o devido descarte e reuso do lixo eletrônico.
\end{abstract}

Palavras-chave: Lixo eletrônico; Formas de descarte; Reuso.

ABSTRACT: This paper aims to address the problem of e-waste and the importance of its correct disposal and reuse it through a case study with Administration students of the Faculty Vale Ipojuca (FAVIP/DEVRY). The methodological procedures used in the study were

\footnotetext{
${ }^{1}$ (FAVIP/DEVRY) lholanda@ favip.edu.br

${ }^{2}$ (FAVIP/DEVRY) hchaves@favip.edu.br

3 (FAVIP/DEVRY) renatoatual@hotmail.com .

${ }^{4}$ (UTFPR) acfrancisco@gmail.com
}

ReLAInEP - Revista Latino-America de Inovação e Engenharia de Produção, Curitiba, PR, Brasil, v. 3, n. 4, p. 106-124, 2015. 


\section{ReLAInEP}

applied research, qualitative, descriptive case study. The population is the students of the Administration, enrolled in half of 2012.2, representing (530) five hundred and thirty students. The sample is now characterized as simple random, in that each member of the population had an equal opportunity to be included that is composed of 110 pupils. The instrument used for data collection consisted of a questionnaire consisting of six questions with the primary objective of checking the students' perception on how to reuse and disposal of electronic waste. Through the information obtained is possible to infer that the students' perception about the correct way of disposal and reuse of e-waste is still confusing. It was satisfied that the vast majority of respondents did not have detailed knowledge of what is junk, its negative consequences for the environment and the health of living beings, and can realize the reuse and proper disposal of electronic waste.

Key-words: Junk; Forms of disposal; Reuse.

RESUMEN: Este trabajo tiene como objetivo abordar el problema de los desechos electrónicos y la importancia de su correcta eliminación y volver a utilizar esto a través de un estudio de caso con los estudiantes de la Facultad de Gestión de Valle de Ipojuca (FAVIP / DEVRY). Los procedimientos metodológicos utilizados en el estudio fueron la investigación aplicada, el estudio cualitativo, descriptivo y caso. La población se ocupa de los estudiantes del curso de Administración, se matriculó en la mitad de 2012-2, lo que representa (530) quinientos treinta estudiantes. Dado que la muestra se caracteriza por ser aleatoria simple, en el que cada miembro de la población tiene la misma oportunidad de ser incluido, este se compone de 110 alumnos. El instrumento utilizado para la recolección de datos consistió en un cuestionario que consta de seis preguntas con el objetivo primordial para verificar la percepción de los estudiantes sobre cómo disponer de ellos ya la reutilización de los residuos electrónicos. A través de es posible la información obtenida para inferir que la percepción de los estudiantes acerca de la forma correcta de eliminación y reutilización de los residuos electrónicos es todavía confuso, dado que se puede demostrar que la gran mayoría de los encuestados no tienen un conocimiento profundo de lo que es correo basura, sus consecuencias negativas para el medio ambiente y para la salud de los seres vivos y pueden realizar la correcta eliminación y reutilización de los residuos electrónicos.

Palabras clave: La basura electrónica; La eliminación de formas; Reutilización.

\section{INTRODUÇÃO}

Nos dias atuais, é notória a crescente preocupação por parte das diversas organizações por questões ambientais. Essa afirmação inicial é confirmada pela escassez dos recursos naturais, pelas novas Leis e através das várias ações impostas pela sociedade.

ReLAInEP - Revista Latino-America de Inovação e Engenharia de Produção, Curitiba, PR, Brasil, v. 3, n. 4, p. 111-129, 2015. 


\section{ReLAInEP}

Para se adequar a essa nova realidade, as empresas precisam desenvolver mecanismos estratégicos para garantir a sua sobrevivência e melhorar seus níveis de competitividade, sem deixar de lado a questão ambiental.

Diante desse contexto inicial, a logística reversa passa a ser considerada uma ferramenta estratégica que tenta revalorizar os diversos materiais, reduzindo os custos dos insumos para as empresas, agregando valor ao produto, satisfazendo as necessidades dos clientes e melhorando a imagem da organização, além de contribuir imensamente com a preservação do meio ambiente.

Os avanços tecnológicos ajudaram a apressar os ciclos de vida dos produtos eletrônicos, gerando os resíduos tecnológicos. Esses precisam de coleta, armazenamento e destinação adequada. É nesse sentido que entra a necessidade de se estudar a relação entre logística reversa e lixo eletrônico, mais especificamente as formas de descarte e reuso desse material.

De acordo com Leite (2009), O lixo eletrônico é constituído por aparelhos eletrodomésticos e por componentes eletrônicos que podem ser utilizados tanto para uso doméstico, como para uso comercial e também na área de serviços, contanto que esteja em desuso, fim de vida útil e sujeitos à disposição final, neles estando inclusos televisores, telefones celulares, velhos computadores, baterias, equipamentos de áudio, dentre outros.

Ainda segundo o autor, os problemas causados por esses resíduos, de sua reciclagem inapropriada e de sua disposição final de forma ineficiente, causam grandes danos à saúde, além de prejudicar o meio ambiente.

Em razão dessa realidade explicitada nos parágrafos anteriores, surgem dúvidas sobre o que fazer a respeito do lixo eletrônico e quais prejuízos o mesmo pode trazer ao meio ambiente e, consequentemente, à saúde e à vida das pessoas. Ante a contextualização inicial, formulou-se o objetivo da pesquisa: Investigar a percepção do aluno do Curso de Administração da Faculdade do Vale do Ipojuca (FAVIP/DEVRY) sobre a forma de descarte e reuso do lixo eletrônico.

\section{FUNDAMENTAÇÃO TEÓRICA - EVOLUÇÃO DA LOGISTICA}

Com o abandono da vida nômade e extrativista, o homem deu início às atividades produtivas organizadas, e o armazenamento, a distribuição e a estocagem de produtos

ReLAInEP - Revista Latino-America de Inovação e Engenharia de Produção, Curitiba, PR, Brasil, v. 3, n. 4, p. 111-129, 2015. 


\section{ReLAInEP}

aumentaram, possibilitando o controle da produção (FLEURY, WANK e FIGUEIREDO, 2000, p. 27).

Entretanto, a logística ganhou maior destaque nas operações militares pelo aperfeiçoamento das operações. De acordo com Dias (2005), desde os tempos bíblicos os líderes militares já se utilizavam da logística. As guerras eram longas, geralmente distantes e eram necessários constantes deslocamentos de recursos.

Novaes (2007) complementa que,

[...] ao decidir avançar suas tropas seguindo uma determinada estratégia militar, os generais precisavam ter, sob suas ordens, uma equipe que providenciasse o deslocamento, na hora certa, de munição, víveres, equipamentos e socorro médico para o campo de batalha. Por se tratar de um serviço de apoio, sem o glamour da estratégia bélica e sem o prestígio das batalhas ganhas, os grupos logísticos militares trabalhavam em silêncio, na retaguarda (NOVAES, 2007, p.31 e 32).

Após o período de guerras e batalhas, o avanço da tecnologia e a necessidade dos locais atingidos se reerguerem, tornaram a logística um dos elementos mais importantes presentes nas estratégias das organizações, desenvolvendo-se no ambiente organizacional. Novaes (2007) ainda afirma que, a logística era confundida com o transporte e a armazenagem de produtos e hoje é o ponto crucial da cadeia produtiva integrada.

Diante do contexto inicial, a logística resgata diversas abordagens, que serão apresentadas no Quadro 1.

Quadro 1 - Principais autores e conceitos de logística

\begin{tabular}{|c|l|}
\hline Autores & \multicolumn{1}{c|}{ Conceito } \\
\hline Ballou (1993) & $\begin{array}{l}\text { Logística é o estudo da administração dos fluxos de bens e serviços e da informação } \\
\text { associada que os põem em movimento. }\end{array}$ \\
\hline $\begin{array}{c}\text { ASLOG - } \\
\text { Associação Brasileira } \\
\text { de Logística }\end{array}$ & $\begin{array}{l}\text { Logística é a função sistêmica de otimização do fluxo de materiais e informações de } \\
\text { uma organização. Integra duas ou mais atividades gerenciais ou operacionais, } \\
\text { planejando, implementando e controlando o fluxo eficiente de materiais e } \\
\text { informações, do ponto de origem ao ponto de destino, com o propósito de adequá-los } \\
\text { às necessidades dos fornecedores e clientes. }\end{array}$ \\
\hline Novaes (2007, p. 35) & $\begin{array}{l}\text { Logística é o processo de planejar, implementar e controlar de maneira eficiente o } \\
\text { fluxo e a armazenagem de produtos, bem como os serviços e informações associados, } \\
\text { cobrindo desde o ponto de origem até o ponto de consumo, com o objetivo de atender } \\
\text { aos requisitos do consumidor. }\end{array}$ \\
\hline $\begin{array}{c}\text { CLM - Council of } \\
\text { Management } \text { USA }\end{array}$ & $\begin{array}{l}\text { É o processo de planejar, implementar e controlar eficientemente, ao custo correto, o } \\
\text { fluxo e armazenagem de matérias-primas e estoque durante a produção e produtos } \\
\text { acabados, e as informações relativas a estas atividades, desde o ponto de origem até o } \\
\text { ponto de consumo, visando a atender aos requisitos do cliente. }\end{array}$ \\
\hline \multicolumn{2}{|c|}{} \\
\hline
\end{tabular}

Fonte - Autores, (2012).

ReLAInEP - Revista Latino-America de Inovação e Engenharia de Produção, Curitiba, PR, Brasil, v. 3, n. 4, p. 111-129, 2015. 


\section{ReLAInEP}

A partir das definiçõoes pode-se entender que não existe um consenso entre os autores sobre o conceito, porém, é possível observar que, a logística está relacionada com o planejamento, implementação e controle do fluxo e armazenagem de produtos e informações de forma econômica, satisfazendo as necessidades dos clientes.

Segundo Novaes (2007), durante muito tempo nas empresas às atividades logísticas foram encaradas como simples atividades de apoio que não agregavam nenhum valor ao produto, sem implicações na estratégia ou geração de negócios.

Devido a esta ausência de valor, muitas empresas utilizam a logística para obter o sucesso empresarial, como descrito por Leite (2009), a logística empresarial assume um papel relevante no planejamento e controle do fluxo de materiais e de produtos desde a entrada na empresa até sua saída como produto finalizado. Portanto, a redução dos custos, tempo e volume de produtos, torna-se um grande diferencial diante de um mercado tão competitivo.

Outro ensinamento de Bowersox e Closs (2010, p. 20) é que, o que faz a logística contemporânea interessante é o desafio de tornar os resultados combinado da integração interna e externa numa das competências centrais da empresa. É de grande valia o bom relacionamento entre todos os processos de fluxos de produção e informação.

Explica ainda o mesmo autor que, quando as operações logísticas estão fortemente integradas e são consideradas uma competência-chave, elas podem servir como base para a obtenção de vantagens estratégicas. Novaes (2007) completa ainda que, deve-se focar na integração entre todos os elementos da cadeia de suprimento, dando uma maior importância ao consumidor, buscando sempre satisfazê-lo.

Com o decorrer do tempo, observa-se que a logística vem apresentado várias modificações, deixando de ser uma simples atividade secundária para ocupar um espaço estratégico nas organizações, e pode ser melhor compreendido ao analisar seu processo evolutivo.

Relata Novaes (2007), que o processo da evolução da logística é composto por quatro fases: Atuação Segmentada, Integração Rígida, Integração Flexível e Integração Estratégica (SCM). A seguir, é possível observar resumidamente as características de cada fase da logística:

ReLAInEP - Revista Latino-America de Inovação e Engenharia de Produção, Curitiba, PR, Brasil, v. 3, n. 4, p. 111-129, 2015. 


\section{ReLAInEP}

-- Primeira fase: atuação independente; estoques em todas as etapas na cadeia de suprimento; EOQ - lote econômico para redução do custo de transporte; grande quantidade e pouca variedade; alto custo de pedido.

-- Segunda fase: redução de estoques; grande variedade de produtos disponibilizados no mercado; início da revolução da informática; início da utilização da multimodalidade do transporte de cargas.

-- Terceira fase: desenvolvimento intensivo da informática; integração parcial entre fornecedores e clientes; satisfação dos clientes.

-- Quarta fase: tratamento da logística como uma questão estratégica; agentes da cadeia de suprimento trabalhando de forma mais próxima; fornecedores e clientes trocam informações antes consideradas confidenciais; suppy chain management e logística reversa.

Dentre as diversas características das fases da Logística, na quarta pode-se observar a Logística Reversa (objeto de estudo) que, segundo Leite (2009) é a parte da logística empresarial que:

\footnotetext{
opera e controla o fluxo e as informações logísticas correspondentes do retorno dos bens de pós-venda e de pós-consumo ao ciclo de negócios ou ao ciclo produtivo, por meio dos canais de distribuição reversos, agregando-lhes valor de diversas naturezas: econômico, de prestação de serviços, ecológico, legal, logístico, de imagem corporativa, dentre outros. (LEITE, 2009, p. 17).
}

A logística é tida como o gerenciamento do fluxo de materiais do seu ponto de aquisição até o seu ponto de consumo. No entanto, existe também um fluxo logístico reverso, do ponto de consumo até o ponto de origem, que precisa ser gerenciado (LACERDA, 2009, p. 01). O próximo tópico abordará com mais detalhes sobre o retorno dos produtos - logística reversa.

\subsection{Logística Reversa}

Os primeiros estudos sobre a logística reversa são encontrados nas décadas de 1970 e 1980, tendo seu principal foco relacionado ao retorno de bens a serem processados em reciclagem de materiais. (LEITE, 2009, p. 15).

ReLAInEP - Revista Latino-America de Inovação e Engenharia de Produção, Curitiba, PR, Brasil, v. 3, n. 4, p. 111-129, 2015. 


\title{
ReLAInEP
}

Para o mesmo autor, o aumento da importância nesse ramo surgiu pelo crescimento da preocupação com o meio ambiente e com a preocupação de atender as necessidades dos clientes obtendo menores custos.

Com essa preocupação ambiental, o governo instituiu legislações que buscam conscientizar as empresas para investir e equacionar o fluxo reverso dos produtos de pósconsumo e, o não cumprimento poderá afetar a imagem e reputação da organização diante da sociedade.

Tadeu et al. (2012) reforça que a logística pode ser entendida como um processo estratégico, permitindo que se torne um diferencial competitivo. Ainda cita alguns critérios para esse diferencial: retorno de produtos, valor econômico agregado, imagem, aspectos ecológicos, imagem corporativa e atendimento à legislação.

A importância e o crescimento da Logística reversa ofereceram aos autores diversas condições para expor seus conceitos.

Dornier et al (2000) apresenta que,

\begin{abstract}
A logística é a gestão de fluxos entre funções de negócio. A definição atual de logística engloba maior amplitude de fluxos que no passado. Tradicionalmente, empresas incluíam a simples entrada de matérias-primas ou o fluxo de saída de produtos acabados em sua definição de logística. Hoje, no entanto, essa definição expandiu-se e inclui todas as formas de movimentos de produtos e informações [...]. Portanto, além dos fluxos diretos tradicionalmente considerados, a logística moderna engloba, entre outros, os fluxos de retorno de peças a serem reparadas, de embalagens e seus acessórios, de produtos vendidos devolvidos e de produtos usados/consumidos a serem reciclados. (DORNIER et al., 2000, p.39).
\end{abstract}

Complementa Bowersox e Closs (2010), sobre a ideia do "apoio ao ciclo de vida" como um dos objetivos do projeto logístico moderno, referindo-se ao prolongamento da Logística além do fluxo direto dos materiais e a necessidade de considerar os fluxos reversos de produtos em geral.

O autor ainda destaca sobre a importância do descarte e reciclagem dos produtos, e sobre a preocupação ambiental das empresas:

A logística reversa, como competência, decorrente da atenção mundial a questões ambientais, requer a capacidade de reciclar ingredientes e materiais de embalagem. $\mathrm{O}$ apoio ao ciclo de vida, em termos modernos, significa dar apoio logístico integral. (BOWERSOX; CLOSS, 2010, p. 51).

ReLAInEP - Revista Latino-America de Inovação e Engenharia de Produção, Curitiba, PR, Brasil, v. 3, n. 4, p. 111-129, 2015. 


\section{ReLAInEP}

A logística reversa atua em duas grandes áreas no processo logístico, o autor Leite (2009) destaca: Logística reversa de pós-consumo e de pós-venda.

A de pós-consumo planeja, opera e controla o fluxo de retorno dos produtos de pós consumo ou de seus materiais constituintes classificados em função de seu estado de vida e origem: "Em condições de uso", "Fim de vida útil”, e "Resíduos Industriais" (LEITE, 2009, p. 20).

Já a de pós-venda planeja, opera e controla o fluxo de retorno dos produtos de pósvenda por motivos agrupados nas classificações: "Garantia/Qualidade", "Comerciais" e de “Substituição de Componentes”. (LEITE, 2009, p. 19).

Conforme Leite (2009) os bens produzidos são divididos em três categorias: os bens descartáveis, os bens semiduráveis e os bens duráveis, classificados de acordo com a sua vida útil. Explica Tadeu et al. (2012, p.32), que a vida útil de um bem é tida como o tempo transcorrido desde a sua produção original até o momento em que o primeiro possuidor se desfaz dele.

Com a alta demanda de produtos fabricados e, consequentemente o rápido descarte dos mesmos, Leite (2009) afirma que há um aumento na quantidade de itens a ser manipulada nos canais de distribuição diretos, exigindo giros de estoque crescentes para manter o 'frescor' dos produtos em geral e, portanto, maiores quantidades de produtos a retornar.

Complementa Tadeu et al. (2012) que muitos desses resíduos são descartados incorretamente, dificultando o manuseio e o seu reaproveitamento, implicando custos, danos e prejudicando o meio ambiente.

Leite (2009) ainda explica que,

[...] o aumento da velocidade de descarte dos produtos de utilidade após seu primeiro uso, motivado pelo nítido aumento da descartabilidade dos produtos em geral, não encontrando canais de distribuição reversos de pós-consumo devidamente estruturados e organizados, provoca desequilíbrio entre as quantidades descartadas e as reaproveitadas, gerando um enorme crescimento de produtos de pós-consumo. Um dos mais graves problemas ambientais urbanos da atualidade é a dificuldade de disposição do lixo urbano (LEITE, 2009, p. 21).

Após explanação sobre os canais reversos e a classificação dos bens que iram percorrer esses canais, o próximo tópico aborda especificamente o lixo eletrônico, objeto do estudo.

ReLAInEP - Revista Latino-America de Inovação e Engenharia de Produção, Curitiba, PR, Brasil, v. 3, n. 4, p. 111-129, 2015. 


\section{ReLAInEP}

\subsection{Lixo Eletrônico}

A expressão lixo eletrônico pode ser encontra na literatura com outras denominações como resíduo eletrônico, lixo tecnológico, lixo digital etc.

Esse tipo de resíduo constitui todo ou qualquer produto de origem tecnológica que se torna obsoleto ou inservível, acabando por serem descartados ou jogados no lixo, incluindo nesse contingente, de acordo com a Wast fron Eletrical and Electronic Equipment (WEE), Grandes eletrodomésticos; Pequenos eletrodomésticos; TI e Telecoms; Equipamentos que utilizem lâmpadas; Ferramentas elétricas e eletrônicas; Brinquedos, lazer e esportes; Equipamentos médicos, Equipamentos de monitoramento; Equipamento de autodistribuição (MIGUEZ, 2010 p. 26).

Importante aqui destacar que a despeito da existência de uma extensa gama de categorias de origem, grande parte do lixo eletrônico é composta justamente por computadores e outros produtos do setor de informática, materiais esses que se tornam obsoletos cada vez mais rápidos, muitas vezes até mesmo antes de saírem das lojas, o que, por sua vez, representa um grande problema para as empresas, para a sociedade e, consequentemente, para o meio ambiente (BORGES, 2007; ABINEE, 2007; MEIRELLES, 2010).

$\mathrm{Na}$ grande maioria dos casos, tais produtos são descartados justamente por serem ultrapassados por inovações tecnológicas que surgem em espaços cada vez menores de tempo (obsolescência tecnológica), ou pela falência dos mecanismos do produto (MIGUEZ, 2010).

Contudo, como pertinentemente leciona Oliveira (2009), as trocas constantes dos produtos eletroeletrônicos não acontecem somente pela deficiência após certo tempo de uso, mas sim muitas vezes pela vaidade das pessoas em consumir e exibir um novo aparelho com designer e funções mais modernas do que o que anteriormente possuíam.

Os problemas do descarte incorreto desses produtos podem causar prejuízos, conforme Moreira (2007), no lixo eletrônico encontram-se elementos como chumbo, mercúrio, cádmio, arsênio e berílio, elementos esses que podem causar danos ao sistema nervoso, ao sistema cerebral, ao sistema sanguíneo, ao fígado, aos ossos, aos rins, aos pulmões, bem como também doenças de pele, câncer de pulmão, desordens hormonais e reprodutivas e, ainda, problemas respiratórios.

ReLAInEP - Revista Latino-America de Inovação e Engenharia de Produção, Curitiba, PR, Brasil, v. 3, n. 4, p. 111-129, 2015. 


\section{ReLAInEP}

Ainda segundo Moreira (2007),

[...] tem-se que, do ponto de vista ambiental, as substâncias mais problemáticas presentes no lixo eletrônico são justamente os metais pesados, gases de efeito estufa, substâncias halogenadas, amianto e arsênio, substâncias que apresentam elevado potencial de contaminação do ambiente e dos indivíduos, quer seja durante a disposição final, quer seja no processo de recuperação e reciclagem, quando se torna importante destacar que os aparelhos eletrônicos modernos podem chegar a conter até 60 elementos químicos variados, alguns valiosos, outros bastante perigosos, e outros que são as duas coisas ao mesmo tempo (MOREIRA, 2007).

Segundo Carpanez, (2007) existem dez mandamentos para se evitar tanto lixo eletrônico:

1. Pesquise: Conheça o fabricante de seu produto, bem como suas preocupações ambientais e o descarte do bem de consumo mais tarde.

2. Prolongue: Cuide bem de seus produtos e aprenda a evitar os constantes apelos de troca, prolongue ao máximo sua vida útil.

3. Doe: Doe para alguém que vá usá-lo, além de ajudar, evita que alguém compre um novo.

4. Recicle: Procure por pontos de coleta que fazem reciclagem.

5. Substitua: Produtos que agregam várias funções, como uma multifuncional, consomem menos energia do que cada aparelho usado separadamente.

6. Informe-se: Torne-se adepto ao consumo responsável, sabendo as consequências que seus bens causam ao ambiente.

7. Opte pelo original: Cuidado com piratarias, os produtos não seguem políticas de preservação do ambiente.

8. Pague: Os produtos dos fabricantes que oferecem programas de preservação ambiental podem ser mais caros, vale a pena optar pela alternativa "verde".

9. Economize energia: Opte pelo produto que consome menos energia.

10. Mobilize: Passe informações sobre lixo eletrônico para frente, pois muitos usuários de tecnologia não se dão conta do tamanho do problema.

No Brasil a legislação vigente para esse tipo de material trata da Lei Federal no 12.305, de 2 de agosto de 2010, política nacional de resíduos sólidos, em seu art. 33, estabelece que é de responsabilidade dos fabricantes, importadores, distribuidores e comerciantes, a

ReLAInEP - Revista Latino-America de Inovação e Engenharia de Produção, Curitiba, PR, Brasil, v. 3, n. 4, p. 111-129, 2015. 


\section{ReLAInEP}

estruturação e implementação de sistemas de logística reversa para a reciclagem ou destinação correta desse material.

Diante dessa realidade, pode-se constatar a relevância que a logística reversa adquire nesse cenário, possibilita tanto o desagravo dos impactos socioambientais causados por produtos eletroeletrônicos, quanto também proporciona o ganho de eficiência e sustentabilidade das operações nas organizações.

\section{FORMATAÇÃO DE TABELAS, GRÁFICOS, TABELAS E FIGURAS}

\subsection{Classificação da Pesquisa}

A pesquisa é classificada como aplicada, qualitativa, exploratória e estudo de caso.

Pode ser considerada aplicada, esse tipo de pesquisa objetiva gerar conhecimentos para aplicação prática e dirigida à solução de problemas específicos. Envolve verdades e interesses locais (SILVA e MENEZES, 2005 p. 20). Os conhecimentos gerados pela pesquisa podem nortear empresas e poder público a desenvolver ações relacionadas ao descarte e reuso do lixo eletrônico.

Já a pesquisa qualitativa considera que há uma relação dinâmica entre o mundo real e o sujeito, isto é, um vínculo indissociável entre o mundo objetivo e a subjetividade do sujeito que não pode ser traduzido em números (SILVA e MENEZES, 2005 p. 20). O uso da abordagem qualitativa nessa pesquisa permitiu relacionar a função da logística reversa com o problema do lixo eletrônico.

A Pesquisa exploratória visa proporcionar maior familiaridade com o problema com vistas a torná-lo explícito ou a construir hipóteses. Envolve levantamento bibliográfico e entrevistas (SILVA; MENEZES, 2001 p.20). Como se deseja, investigar a percepção do aluno do curso de Administração da FAVIP/DEVRY sobre a forma de descarte e reuso do lixo eletrônico, a abordagem exploratória é a mais indicada.

Silva e Menezes (2001, p. 21) afirmam que o estudo de caso envolve o estudo profundo e exaustivo de um ou poucos objetos, de maneira que se permita o seu amplo e detalhado conhecimento. Já que nesse trabalho a intenção é investigar detalhadamente a percepção do aluno do curso de Administração sobre a forma de descarte e reuso do lixo eletrônico,

ReLAInEP - Revista Latino-America de Inovação e Engenharia de Produção, Curitiba, PR, Brasil, v. 3, n. 4, p. 111-129, 2015. 


\section{ReLAInEP}

especificamente da Faculdade do Vale do Ipojuca (FAVIP/DEVRY), considerou-se o estudo de caso o mais indicado.

\subsection{População e Amostra}

População é a totalidade de indivíduos que possuem as mesmas características definidas para um dado estudo; ao passo que a amostra é parte da população ou do universo, selecionada de acordo com uma regra ou plano (SILVA e MENEZES, 2005). Nesse sentido, tem-se que a população pesquisada é composta pelos estudantes do Curso de Administração da Faculdade Vale do Ipojuca, portanto o número de estudantes matriculados no semestre de 2012.2 foi de 530 alunos.

Já a amostra é caracterizada como casual simples, na medida em que cada elemento da população teve igual oportunidade de ser incluída na amostra, essa que para ser definida seguiu o cálculo abaixo, quando $\mathrm{n}=$ amostra calculada; $\mathrm{N}=$ população; $\mathrm{Z}=$ variável normal padronizada associada ao nível de confiança; $\mathrm{p}=$ verdadeira probabilidade do evento; $\mathrm{e}=$ erro amostral (SILVA e MENEZES, 2005).

$$
n=\frac{N \cdot Z^{2} \cdot p \cdot(1-p)}{Z^{2} \cdot p \cdot(1-p)+e^{2} \cdot(N-1)}
$$

Considerando que para o cálculo da amostra o estudo envolve variáveis categóricas quando procura um resultado que indique qual é o percentual de elementos com uma dada característica, utilizou-se aqui um percentual mínimo de 90\%, que resultou em 110 alunos.

\subsection{Instrumento de Coleta de dados}

Para esse estudo foi escolhido como instrumento de coleta de dados o questionário, aplicado com os alunos do Curso de Administração da Faculdade do Vale do Ipojuca (FAVIP), que tomaram conhecimento da pesquisa e de sua participação, fornecendo seu consentimento por meio do Termo de Consentimento Livre e Esclarecido.

O questionário é composto de seis (6) perguntas, com o objetivo primordial de verificar a percepção dos alunos sobre a forma de descarte e reuso do lixo eletrônico. As respostas são de múltipla escolha e também foi aberto espaço para que o respondente apresente seus comentários adicionais, caso necessário.

ReLAInEP - Revista Latino-America de Inovação e Engenharia de Produção, Curitiba, PR, Brasil, v. 3, n. 4, p. 111-129, 2015. 


\section{ReLAInEP}

\subsection{Tratamento dos dados}

Como já explicitado no tópico anterior, a coleta de dados aconteceu através da aplicação do questionário. Após a coleta, partiu-se para a sua tabulação e análise. Os dados foram reunidos em Tabelas do Microsoft Word, versão 2007. A análise das variáveis aconteceu sem auxílio de ferramentas estatísticas, esta foi realizada com através de porcentagem.

\section{RESULTADOS}

Os dados colhidos através do questionário foram agrupados nos Tabelas a seguir. $\mathrm{O}$ primeiro questionamento refere-se ao nível de conhecimento dos entrevistados acerca do lixo eletrônico e pode ser visualizado no Tabela 1.

Os seis (6) respondentes que assinalaram não possuir nenhum conhecimento sobre o assunto, não precisaram seguir nas demais perguntas do questionário.

Tabela 1 - Conhecimento dos entrevistados acerca do lixo eletrônico

\begin{tabular}{l|c}
\hline Conhecimento dos entrevistados acerca do lixo eletrônico & $\%$ \\
\hline Nenhum conhecimento. & $5,45 \%$ \\
\hline Pouco conhecimento. & $61,81 \%$ \\
\hline Bom nível de conhecimento. & $29,10 \%$ \\
\hline Excelente nível de conhecimento. & $3,64 \%$ \\
\hline \multicolumn{2}{c}{ Fonte - Pesquisa de campo (2012) }
\end{tabular}

Fonte - Pesquisa de campo (2012)

Como é possível observar uma parcela significativa da amostra respondeu possuir nenhum ou pouco conhecimento sobre o que é lixo eletrônico, alguns respondentes relacionaram esse conceito ao de mala direta (spam) e não com produtos eletrônicos que já chegaram ao final da sua vida útil.

Os demais respondentes afirmaram que tomaram conhecimento sobre o assunto já na faculdade e/ou através das ferramentas de comunicação como a televisão e internet, porém não houve uma maior preocupação em aprofundar no tema ou simplesmente não sentiram interesse. A pequena parcela que respondeu ter excelente conhecimento sobre o assunto confirmou a necessidade do descarte correto e os perigos provenientes desse tipo de resíduos.

A partir da análise dos dados é possível inferir que os produtos eletrônicos chegaram a todas as classes da população, porém o debate sobre o descarte e as formas de reuso desse material ainda não é clara nem divulgada, principalmente para os consumidores, necessitando

ReLAInEP - Revista Latino-America de Inovação e Engenharia de Produção, Curitiba, PR, Brasil, v. 3, n. 4, p. 111-129, 2015. 


\section{ReLAInEP}

uma maior atenção das empresas. O próximo critério observado refere-se ao que deve ser considerado como lixo eletrônico, esses dados estão no Tabela 2.

Tabela 2 - O que deve ser considerado lixo eletrônico

\begin{tabular}{l|c}
\hline O que deve ser considerado lixo eletrônico & \% \\
\hline Televisão. & $55,45 \%$ \\
\hline Computador. & $70 \%$ \\
\hline Celular. & $73,64 \%$ \\
\hline Lâmpadas. & $\mathbf{3 5 , 4 5 \%}$ \\
\hline Pilhas. & $52,72 \%$ \\
\hline Baterias. Fonte - Pesquisa de campo (2012) & $59,09 \%$ \\
\hline \multicolumn{2}{c}{}
\end{tabular}

De acordo com as respostas dispostas no Tabela 3 é possível afirmar que os respondentes consideram principalmente celulares, computadores, baterias os principais produtos geradores de lixo eletrônico, porém vinculam bem menos a esse conceito produtos como pilhas e lâmpadas.

O fato das pessoas não relacionarem o conceito aos produtos corretos acontece devido ao pouco conhecimento dos respondentes sobre o tema. No Tabela 3 foram levantadas informações sobre os motivos que levam ao descarte de produtos.

Tabela 3 - Motivos que levam os entrevistados a descartarem produtos e transformá-los em lixo eletrônico

\begin{tabular}{l|c}
\hline $\begin{array}{l}\text { Motivos que levam os entrevistados a descartarem } \\
\text { produtos e transformá-los em lixo eletrônico }\end{array}$ & $\%$ \\
\hline Funções adicionais dos aparelhos novos. & $18,19 \%$ \\
\hline Defeitos. & $40 \%$ \\
\hline Fora da moda. & $6,36 \%$ \\
\hline Fim da vida útil. & $35,45 \%$ \\
\hline \multicolumn{2}{c}{ Fonte - Pesquisa de campo (2012) }
\end{tabular}

Os principais motivos que levam as pessoas a descartarem os produtos e esses se transformarem em lixo eletrônico são os defeitos e o vim da vida útil. Os respondentes alegaram que boa parte dos produtos tem praticamente "prazo de validade pré-determinado" e quando quebram as peças de reposição são tão caras que não vale a pena realizar o concerto.

Uma informação interessante, as pessoas afirmaram que, mesmo com novas funções nos aparelhos, elas preferem usá-los até chegar ao fim da vida útil, só uma pequena parcela realiza a substituição dos seus produtos. Já em relação a moda, o enorme apelo das ações de marketing, também não influenciam as pessoas trocarem seus produtos. $\mathrm{O}$ próximo

ReLAInEP - Revista Latino-America de Inovação e Engenharia de Produção, Curitiba, PR, Brasil, v. 3, n. 4, p. 111-129, 2015. 


\section{ReLAInEP}

questionamento refere a forma de descarte do lixo eletrônico, essas informações estão no Tabela 4.

Tabela 4 - Forma como os entrevistados fazem o descarte do seu lixo eletrônico

\begin{tabular}{l|c}
\hline Forma como os entrevistados fazem o descarte do seu lixo eletrônico & \% \\
\hline Não descarto, guardo na dispensa da minha casa. & $39,10 \%$ \\
\hline Descarto através da coleta de lixo, misturo com outros tipos de lixo. & $40 \%$ \\
\hline Procuro um posto de coleta para descartar esse tipo de lixo. & $13,63 \%$ \\
\hline Faço doação desse material para institutos de caridade. & $7,27 \%$ \\
\hline
\end{tabular}

Fonte - Pesquisa de campo (2012)

Para o quesito descarte do lixo eletrônico, é possível observar que quase $80 \%$ da amostra pesquisada não sabe como fazê-lo ou realiza de maneira incorreta misturando com os demais resíduos. As pessoas forneceram algumas informações que merecem destaque: nas suas cidades desconhecem pontos de coleta e, produtos pequenos, como pilhas e baterias, vão ficando armazenados nas gavetas ou nas suas dispensas, quando não possuem espaços fazem o descarte incorreto.

Oura informação importante fornecida por alguns respondentes é que na faculdade onde estudam (FAVIP) não dispõem de pontos de coleta para esse tipo de material, o que poderia resolver o problema das pessoas que moram em outras cidades.

Para as pessoas que moram em Caruaru-PE, eles afirmaram que nos dois shoppings, algumas empresas dispõem de pontos, onde são coletados alguns produtos e, a partir dessas ações isoladas, levam o lixo eletrônico para ser descartado corretamente. Também afirmaram que poucas ações de coleta são realizadas por instituições de caridade. A próxima pergunta é sobre às consequências do descarte incorreto, e as pessoas apresentaram as informações do Tabela 5.

Tabela 5- Conhecimento dos entrevistados sobre as consequências do descarte incorreto do lixo eletrônico

\begin{tabular}{l|c}
\hline $\begin{array}{l}\text { Conhecimento dos entrevistados sobre as consequências do descarte } \\
\text { incorreto do lixo eletrônico }\end{array}$ & $\%$ \\
\hline Sim, o descarte incorreto pode contaminar o solo, o ar e o lençol freático. & $87,28 \%$ \\
\hline Não tenho nenhum conhecimento sobre as consequências do descarte. & $12,72 \%$ \\
\hline \multicolumn{2}{c}{ Fonte - Pesquisa de campo (2012) }
\end{tabular}

A maioria dos respondentes afirmaram possuir conhecimento sobre as consequências do descarte incorreto do lixo eletrônico no solo, ar e lençol freático, mas alegaram que por falta de postos de coleta e ausência de informações por parte dos fabricantes, não podem armazenar esse resíduo pelo resto da vida nas suas casas.

ReLAInEP - Revista Latino-America de Inovação e Engenharia de Produção, Curitiba, PR, Brasil, v. 3, n. 4, p. 111-129, 2015. 


\section{ReLAInEP}

Os demais justificaram que nenhuma informação tinha sido repassada até o momento e, que a partir de agora, terão mais cuidado com os problemas do lixo eletrônico.

A partir dessas informações é possível inferir que existe interesse e preocupação por parte das pessoas em fazer a coisa certa, o descarte correto do lixo eletrônico, mas que o ciclo de retorno não depende exclusivamente dos consumidores e também que eles não podem ser responsabilizados totalmente pela destinação incorreta, cabe ações do governo e das empresas. O próximo questionamento é sobre a reciclagem do lixo eletrônico, o Tabela 6 apresenta essas informações.

Tabela 6 - Conhecimento dos entrevistados sobre o fato de o lixo eletrônico poder ser reciclável

\begin{tabular}{l|c}
\hline $\begin{array}{l}\text { Conhecimento dos entrevistados sobre o fato de o lixo eletrônico poder } \\
\text { ser reciclável (reuso) }\end{array}$ & $\%$ \\
\hline Sim, já reparei que existe o símbolo de reciclagem nos produtos. & $81,82 \%$ \\
\hline $\begin{array}{l}\text { Não, nunca reparei nenhum símbolo nesses produtos e também não fui } \\
\text { informado sobre sua reciclagem. }\end{array}$ & $18,18 \%$ \\
\hline \multicolumn{2}{c}{ Fonte - Pesquisa de campo (2012) }
\end{tabular}

Sobre a questão dos produtos, que vão se transformar em lixo eletrônico, poder ser reciclados, os respondentes informaram que essa informação existe sim, normalmente as caixas apresentam símbolos da reciclagem e dos tipos de materiais existentes.

Agora a grande maioria das pessoas alegaram que, informações sobre como realizar o descarte correto desse tipo de produto, não encontra disponível em nenhum local do produto nem da sua embalagem.

Os demais respondentes justificaram que em decorrência do pouco tempo que dispõem, não prestaram atenção nas informações disponíveis nos produtos ou embalagens.

\section{CONSIDERAÇÕES FINAIS}

O presente trabalho foi desenvolvido com a finalidade principal de investigar a percepção do aluno do Curso de Administração da Faculdade do Vale do Ipojuca (FAVIP/DEVRY) sobre a forma de descarte e reuso do lixo eletrônico.

Diante do exposto nos tópicos anteriores, é possível inferir que o lixo eletrônico constitui em um problema atual, grave, e que merece maior atenção por parte da sociedade, dos governos e das organizações.

ReLAInEP - Revista Latino-America de Inovação e Engenharia de Produção, Curitiba, PR, Brasil, v. 3, n. 4, p. 111-129, 2015. 


\section{ReLAInEP}

O descarte incorreto desses produtos eletrônicos e seus resíduos afetam diretamente o meio ambiente, provocando danos graves e, não raras vezes, irreversíveis, especialmente em função de certos tipos de substâncias, causando prejuízos também à saúde dos indivíduos.

Em relação aos dados obtidos na pesquisa, pode-se afirmar que o nível de conhecimento acerca do tema, lixo eletrônico, para a maioria dos alunos respondentes ainda é considerado baixo, revelando a necessidade de ações por parte das empresas e do poder público no sentido de informar os riscos e os prejuízos do descarte incorreto do lixo eletrônico pode acarretar.

Também foi averiguado que os respondentes, detentores de conhecimento sobre os prejuízos do descarte incorreto do lixo eletrônico, não realizam de forma correta ou, muitas vezes armazenam em sua própria residência, pela ausência de coleta especializada ou por falta de postos de coleta nas suas cidades, outros por falta de espaço nas suas dispensas acabam descartando misturados ao lixo comum, trazendo, assim, ainda mais danos ao meio ambiente e também à saúde das pessoas.

Portanto, diante dos dados da pesquisa, pode-se concluir que a falta de maiores informações e esclarecimentos por parte dos fabricantes, bem como também a falta da realização de programas e campanhas para arrecadação de lixo eletrônico também contribui negativamente para o agravamento da questão do descarte do lixo eletrônico, favorecendo ainda mais o descarte indevido e o reuso incorreto desses materiais.

Como sugestão, acredita-se que, em se tratando do problema do lixo eletrônico, o mais correto é investir inicialmente em campanhas de informação, tentando conscientizar as pessoas da importância do tratamento devido ao descarte do lixo eletrônico, bem como também dos efeitos nocivos e prejudiciais que esses materiais podem causar ao meio ambiente e aos seres humanos. Para trabalhos futuros é recomendado ampliação desse estudo para uma gama maior de alunos, como também observar outros pontos críticos no retorno desses produtos.

\section{REFERENCIAS}

ABINEE, Associação Brasileira da Indústria Elétrica e Eletrônica. Disponível em: <http://www.abinee.org.br>. Acesso em: 10 nov. 2012.

ReLAInEP - Revista Latino-America de Inovação e Engenharia de Produção, Curitiba, PR, Brasil, v. 3, n. 4, p. 111-129, 2015. 


\section{ReLAInEP}

BORGES, A. Lixo eletrônico vira montanha de problemas. Computerworld, n. 421, nov. 2004. Disponível em: <http://computerworld.uol.com.br/ mercado/ 2004/11/29>. Acesso em: 10 nov. 2012.

BOWERSOX, D. J., CLOSS, D. J. Logística Empresarial, O Processo de Integração da Cadeia de Suprimento, São Paulo, Editora Atlas, 2009.

Logística empresarial: o processo de integração da cadeia de suprimento. $9^{\mathrm{a}}$ reimpressão. São Paulo: Atlas, 2010.

CARPANEZ, J. 10 mandamentos do lixo eletrônico. In: http://g1.globo.com/noticias/tecnologia/0,,mul87082-6174,00.html acessado em 03 de outubro de 2007

DIAS, J. C. Q. Logística global e macrologística. Lisboa: Edições Silabo, 2005.

DORNIER, P-P; ERNST, R.; FENDER, M.; KOUVELIS, P. Logística e operações globais. São Paulo: Atlas, 2000.

FLEURY, P. F.; WANK, P.; FIGUEIREDO, K. F. Logística Empresarial: a perspectiva brasileira. São Paulo: Atlas, 2000.

LACERDA, L. Logística reversa - Uma visão sobre os conceitos básicos e as práticas operacionais. Sargas, 2009. Disponível em: 〈http://goo.gl/lvFmpS〉. Acesso em: $30 \mathrm{de}$ setembro de 2012.

LEITE, P.R. Logística reversa: meio ambiente e competitividade. São Paulo: Pearson Prentice Hall, 2009.

MEIRELLES, F.S. Tecnologia de informação: 21ª Pesquisa Anual do Uso de TI, 2010. Disponível em:

<http://www.eaesp.fgvsp.br/subportais/interna/relacionad/gvciapesq2010.pdf >. Acesso em: 12 nov. 2012.

MIGUEZ, E.C. Logística reversa como solução para o problema do lixo eletrônico: benefícios ambientais e financeiros. Rio de Janeiro: Qualitymark, 2010.

MOREIRA, D. Lixo eletrônico tem substâncias perigosas para a saúde humana. 2007. Disponível em: <http://idgnow.uol.com.br/computacao_pessoal/2007/04/26/idgnoticia.200704-25.3237126805/>. Acesso em: 12 nov. 2012.

NOVAES, A.G. Logística e gerenciamento da cadeia de distribuição. Rio de Janeiro: Elsevier, 2007.

OLIVEIRA, M. Planeta sustentável. 2009. Disponível em: <http://planetasustentavel.abril.com.br/noticias/lixo/conteudo_417085.shtml>. Acesso em: 11 nov. 2012.

ReLAInEP - Revista Latino-America de Inovação e Engenharia de Produção, Curitiba, PR, Brasil, v. 3, n. 4, p. 111-129, 2015. 


\section{ReLAInEP}

SILVA, E.L.; MENEZES, E.M. Metodologia da pesquisa e elaboração de dissertação. 4. ed. Florianópolis: Laboratório de Ensino à Distância/UFSC, 2005.

TADEU, H. F. B.; et al. Logística Reversa e Sustentabilidade. São Paulo: Cengage Learning, 2012.

ReLAInEP - Revista Latino-America de Inovação e Engenharia de Produção, Curitiba, PR, Brasil, v. 3, n. 4, p. 111-129, 2015. 
ReLAInEP - Revista Latino-America de Inovação e Engenharia de Produção, Curitiba, PR, Brasil, v. 3, n. 4, p. 111-129, 2015. 